\title{
An analysis of radiation knowledge and safety management of radiation professionals according to work characteristics and work functions
}

\author{
K. Choi', T.J. Han'², J.K. Cho² ${ }^{*}$ \\ ${ }^{1}$ Department of Basic Medical Science, Jeonju University, Jeonju, Republic of Korea \\ ${ }^{2}$ Department of Radiological Science, Jeonju University, Jeonju, Republic of Korea
}

\section{- Original article}

*Corresponding author:
Jung Keun Cho,
Fax: + 82632202054
E-mail: cjk0129@naver.com
Revised: June 2015
Accepted: July 2015
Int. J. Radiat. Res., January 2016;
14(1): 31-37
DOI: $10.18869 /$ acadpub.ijrr.14.1.31

\begin{abstract}
Background: Recently, there have been many studies on the harmful effects of radiation and the regulations on radiation safety have been toughened both at the in nation and abroad. This study aims to identify the perceptions and actions taken as to radiation safety, and the degree of knowledge related to radiation held by the radiologists working in large hospitals. Materials and Methods: The research tool used in this study is a structured questionnaire. It is consisted of three parts. The first part was about demographic characteristics with 10 questions. The second part was about basic knowledge with 15 questions. The third part was about the perceptions and actions with 10 questions each. The data was statistically analyzed by $t$-test, ANOVA and I-P analysis. Results: First, the more education the study subjects received, their knowledge of radiation increased even though the result was not statistically significant. Second, there was a statistically significant difference in relation to the gender and the age group in safety management practices. The degree of safety management practice was higher among the men than the women. Third, there was a statistically significant difference at the significant level of 5 percent in all 10 questions on the radiation safety management and the degree of practice. Conclusion: Since there is a growing importance on the radiation safety management, it is imperative to tailor educational programs to trainees' gender, age, educational level and duty in order to make the education program for radiation professionals more teleological.
\end{abstract}

Keywords: Radiation professionals, radiation safety management education, radiation safety perception, radiation safety measure.

\section{INTRODUCTION}

Radiation with a wide range of applications has improved the life of human beings. However, it also causes a variety of diseases. The International Commission on Radiological Protection (ICRP) created and distributed international guideline for the purpose of minimizing the harmful effect of radiation and promoting the safe use of radiation (1).

In recent years, the medical field is making a lot of efforts to minimize the radiation exposure of patients by improving significantly the perception as to the harmful effects of radiation
(2-6). On the aspect of hardware, computed tomography equipment was developed as it substantially reduced the scan time $(7,8)$. On the aspect of software, the degree management system on radiation generation equipment has been settled successfully. As a result, the user-centric radiation test and treatment action was changed to the patient-centric action with the purpose of reducing the amount of radiation exposure ${ }^{(9-13)}$.

As the role of a radiologist is gaining more importance as a health professional, it is very important for a radiologist to obtain expert knowledge as to the specialized field of study in 
terms of saving the life of a patient. Moreover, it is equally important to conduct safety management for themselves (14). To this end, radiologists should complete the segmented and systematic education programs provided by the government since 2014 pursuant to the amended nuclear safety law rather than simply taking a general education program provided by companies. Thus, all radiologists should complete the education for radiation professionals for a certain period, which include such preliminary education as safety management in accordance with the use of nuclear facilities, handling of radioactive substances, defense of radiation obstacle, education on the characteristic of companies and relevant laws on radiation safety.

However, it is imperative to prepare more segmented education programs rather than to conduct education a program without considering gender, age, education level and work function in order to make the education program for radiation professionals conducted by the legislation becomes more teleological education. Thus, there have been several studies that conducted a survey on the knowledge level and safety management attitude of radiation professionals (15-18). However, these studies have not considered the fact that the functions and roles of today's radiologists are segmented. Moreover, these studies have not analyzed in depth the perceptions and actions of radiologists as to safety management. Therefore, this study aims to provide preliminary data for the configuration of segmented education programs by analyzing the differences in radiation knowledge in accordance with the three work functions of radiologists (image medicine, radiation cancer study, nuclide medical study), region (Seoul, Gyeonggi-do and other provinces) and work experience from the perspective of service quality. To this end, this study developed 15 questions that measure the information and knowledge that radiation professionals who have aforementioned three work functions must know as a health professional and 10 questions each for the perceptions and actions based on the previous studies $(19,20)$. The main purpose of this study is to compare the differences as to the radiation knowledge and 'perception-action' in accordance with the three work functions and locations of workplace of related professionals. This study is expected to contribute to the provision of preliminary information in order to conduct efficiently the education for professionals, which aims to reduce the radiation exposure as to patients in addition to radiation professionals.

\section{MATERIALS AND METHODS}

\section{Data collection}

This study selected S Medical Center, S University Hospital and C University Hospital in Seoul and 5 hospitals including $\mathrm{K}$ University Hospital in other metropolitan cities and 10 hospitals including the National C Center and Jeju H Hospital in provinces. This study assigned a certain number of samples for each work function of radiation professionals as to the selected hospitals. Then, this study conducted a survey using convenience sample. The survey was conducted based on a self-reported method for 420 subjects from September 22 to October 24,2014 . The collected questionnaires were analyzed using IBM SPSS ver. 21.

\section{Measurement}

The research tool used in this study is a structured questionnaire that modified and complemented the questionnaires from the previous studies (18-21). More specifically, it is consisted of three parts. The first part was about the demographic characteristics with 10 questions on gender, education level, etc. The second part was about the basic knowledge with 15 questions. The third part was about the perceptions and actions with 10 questions each (table 1). As for the radiation-related knowledge, the subjects were instructed to answer "Yes" or "No" so that they would have less pressure in providing an answer. As for the perceptions and actions related to safety management, they were instructed to answer using a five point Likert scale. 
Table 1. Information on configuration of study tools.

\begin{tabular}{|c|c|c|}
\hline Survey Item & Detailed Information & $\begin{array}{l}\text { Number of } \\
\text { Questions }\end{array}$ \\
\hline Demographic Item & $\begin{array}{l}\text { Gender, Marital status, Education level, Work experience, Work hours, } \\
\text { Number of completed safety education programs, Department, Hospital } \\
\text { size, Hospital location }\end{array}$ & 10 \\
\hline Radiation Knowledge & $\begin{array}{l}\text { Radiation screening, Radiation dose limit, Radiation accident measure, } \\
\text { Radiation waste type and processing method, Neutron generation, } \\
\text { Radioactivity calculation, Knowledge on various regulations, etc. }\end{array}$ & 15 \\
\hline $\begin{array}{l}\text { Safety Management } \\
\text { Perception }\end{array}$ & \multirow{2}{*}{$\begin{array}{l}\text { Wearing personal dosimeter, Wearing personal protection equipment, } \\
\text { Securing stability of workspace, Confirming radiation exposure result, } \\
\text { Measuring radiation, Notifying abnormality, etc. }\end{array}$} & 10 \\
\hline Safety Management action & & 10 \\
\hline
\end{tabular}

\section{Contents of statistical analysis}

As for the radiation knowledge, it was graded based on a total of 15 points with one point for each question. As for the safety management perception and action, "Very likely" was given one point, whereas "Very unlikely" was given 5 points. However, Question 6 for safety management action ("I store the gown with personal dosimeter in the work storage space") was reversely coded in the process of analysis. The specific statistical analysis is as following. First, this study conducted a descriptive statistical analysis, a two-sample independent $t$-test and a one-way analysis of variance as to the knowledge level for the demographic items. Second, this study examined the correlation analysis between radiation knowledge and action. Third, this study conducted an in-depth analysis of 'perception-action' by application of I -P analysis (importance-performance analysis) $(22,23)$ from the marketing perspective. In the above statistical significant tests, we used 5\% significant level.

\section{Importance-performance analysis}

The I-P analysis (importance-performance analysis) is an evaluation technique to analyze relative importance and achievement of each property simultaneously by evaluating the importance before the use of each property and the degree of satisfaction after use of each property in order to measure the satisfaction of users as to the products and services from the perspective of marketing (24). I-P analysis can present problems clearly and it has a high degree of practical utility by facilitating the interpretations of outcomes through evaluating

the expectation and satisfaction simultaneously. The specific objectives of the I-P analysis are to evaluate the user satisfaction by determining how important the properties or characteristics of a particular product are to users and set the relative importance as to each feature and the degree of utilization at the supplier end as to each feature (25). During the interpretation process, the fourth quadrant has a high degree of importance. However, the satisfaction degree thereof is low. Thus, it is an area requiring intensive management. The third quadrant has a high degree of importance and satisfaction. Thus, it is required to have a strategy of maintaining it consistently. The second quadrant has a low degree of both importance and satisfaction. Thus, it can be given lower priority in terms of management. The first quadrant has a low degree of importance; however, it has a high degree of satisfaction. Thus, it is required to have a strategy of removing or improving unnecessary excessive management (figure 1).

This study aims to examine the safety management in accordance with the three radiation related work functions, work

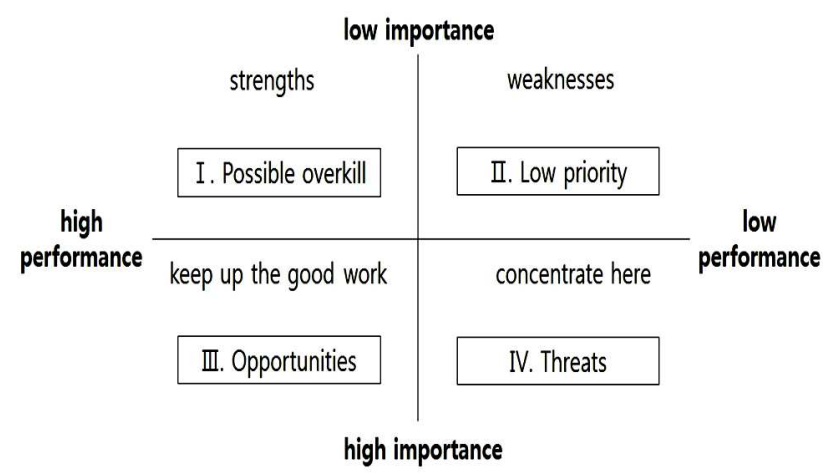

Figure 1. Interpretation of I-P analysis result.

Int. J. Radiat. Res., Vol. 14 No. 1, January 2016 
experiences and education completion by conducting 'perception-action' (P-A) analysis.

\section{RESULTS AND DISCUSSION}

\section{Extent of radiation knowledge according to demographic characteristics}

The results of this study were partially consistent with the results of the previous studies. On that account, caution is required when generalizing the results of this study. However, this study has great significance since it contributes to the provision of preliminary information in order to conduct education efficiently for professionals, which aims to reduce the radiation exposure as to patients in addition to radiation professionals. First, the mean of men was significantly higher than the mean of women in relation to the radiation knowledge. As for the age group, the 20s had the highest level of radiation knowledge. Although it was not statistically significant (5\% significant level), the extent of knowledge was lower among the older age groups. This indicates that people tend to have less radiation-related knowledge as they get older. Thus, it will be necessary to provide additional education to the older age groups. Next, there was no statistically significant difference in terms of marital status and education level (5\% significant level). These findings were not consistent with the findings of previous studies that focused only on the specific region $(15,16)$. The regional distribution of study subjects used in this study is wider than the previous studies. Also, the question about the knowledge level was different from the one of the previous studies ( table 2).

\section{Extent of radiation knowledge according to work characteristics and work functions}

As for the knowledge level in relation to radiation according to the work experience, it was lower for longer years of work experience. Thus, it had a similar result to the age. However, there was no statistically significant difference ( $5 \%$ significant level). As for the number of times they received the education on radiation safety management, the knowledge level would generally increase with more education they received even though the difference was not statistically significant ( $5 \%$ significant level). The finding hereof was consistent with that of the previous study (15). Thus, it is necessary to provide regular education programs on safety management to professionals not only for the health of those professionals but also for the health of patients. The knowledge level of radiation professionals working at the large-sized hospitals with more than 1,000 sickbeds was slightly higher; however, the difference was not statistically significant (5\% significant level). However, there was a statistically significant difference at the significant level of 5 percent in relation to the department and hospital location. In particular, department of nuclear medicine had the highest value, followed by the department of radiation oncology and department of radiology. As for the hospital location, Gyeonggi region including Incheon had the lowest score with 8.69 points, whereas the provincial hospitals in Busan, Chungcheong region, Jella region, Jeju region, etc. had 9.28 points and Seoul had the highest score with 9.52 points (table 3 ).

\section{Extent of safety management practice according to demographic characteristics}

This study examined the extent of safety management practice based on the sum of the 10 questions. "Very likely" was given 1 point. Thus, a lower sum indicates a higher extent of practice. This study found a statistically

Table 2. Extent of radiation knowledge according to demographic characteritics $(* p<0.05)$.

\begin{tabular}{|l|l|l|l|l|}
\hline \multicolumn{2}{|l|}{ Variables } & Mean & SD & $\begin{array}{l}\text { p-value } \\
(\text { t/F })\end{array}$ \\
\hline \multirow{2}{*}{ Gender } & Male & 9.26 & 2.33 & $0.020\left(^{*}\right)$ \\
& Female & 8.54 & 2.40 & \\
\hline \multirow{4}{*}{ Age } & Under 29 & 9.29 & 2.25 & \\
& Under 39 & 9.26 & 2.33 & 0.283 \\
& Under 49 & 9.05 & 2.48 & \\
& Over 50 & 8.51 & 2.29 & \\
\hline Marital & Married & 9.17 & 2.33 & \multirow{2}{*}{0.737} \\
Status & Single & 9.09 & 2.40 & \\
\hline \multirow{2}{*}{ Education } & Undergraduate & 9.18 & 2.36 & \multirow{2}{*}{0.305} \\
\hline Total & Graduate & 8.88 & 2.33 & \\
\hline
\end{tabular}


significant difference in the gender and age group. The extent of safety management practice was higher among the men than the women. The 20s group had the lowest extent of safety management practice. Meanwhile, married professionals and those with graduate degrees were found to have a higher extent of safety management practice. However, the differences thereof were not statistically significant ( $5 \%$ significant level). These findings were not consistent with the findings of the previous studies $(15,19)$. This is because the questions about the regional distribution and knowledge level of study subjects were different (table 4).

\section{Extent of radiation safety management practice according to work characteristics and work functions}

As a result of verifying whether there was a difference in the extent of practice of safety management made up of the 10 questions in accordance with work characteristics and work functions, this study found a significant

Table 3. Extent of radiation knowledge according to work characteristics and work functions ( $* p<0.05)$.

\begin{tabular}{|l|l|l|l|l|}
\hline \multicolumn{2}{|c|}{ Variables } & Mean & SD & $\begin{array}{c}\text { p-value } \\
\text { (t/F) }\end{array}$ \\
\hline \multirow{4}{*}{ Career } & Under 5 years & 9.37 & 2.33 & \\
& 6 10 years & 9.23 & 2.18 & 0.243 \\
& Over 11 years & 8.91 & 2.50 & \\
\hline Working & Under 8 hours & 9.18 & 2.32 & 0.779 \\
Hour & Over 8 hours & 9.11 & 2.39 & \\
\hline Educated & Under 2 times & 8.82 & 2.46 & \\
Number & 3 5 times & 9.13 & 2.44 & 0.131 \\
for Safety & 6 10 times & 8.95 & 2.22 & \\
& Over 11 times & 9.55 & 2.27 & \\
\hline \multirow{5}{*}{ Service } & Radiology & & & \\
Area & Radiation & $7.94(\mathrm{a})$ & 2.28 & $<0.001$ \\
& Oncology & $9.38(\mathrm{~b})$ & 2.14 & $(*)$ \\
& Nuclear & $10.57(\mathrm{c})$ & 1.68 & \\
\hline Hospital & Medicine & & & \\
Size & Under 1,000 beds & 8.96 & 2.42 & 0.201 \\
\hline \multirow{3}{*}{ Region } & Over 1,000 beds & 9.26 & 2.30 & \\
& Seoul & $9.52(\mathrm{~b})$ & 2.10 & \\
& Gyeonggi & $8.69(\mathrm{a})$ & 2.44 & $0.006\left(^{*}\right)$ \\
\hline & Others & $9.28(\mathrm{~b})$ & 2.46 & \\
\hline
\end{tabular}

** (a), (b) and (c) refer to the groups classified based on the result of Duncan post-hoc analysis. difference in the number of times they received the education on radiation safety management, department, hospital size and hospital location. In particular, the degree of practice was generally increased as people received more education. Thus, it is required to continue providing safety management education for practice. In addition, this study found a high extent of safety management practice in large-sized hospitals and those located in Seoul. Lastly, as for the department, the department of nuclear medicine has the highest extent of practice, followed by the department of radiation oncology and department of radiology. Examining the aforementioned findings in association with table 3 , the extent of knowledge and safety management practice related to radiation is higher when they work in the department of nuclear medicine with a higher number of times they receive the education on safety management (table 5).

\section{Perception-action analysis}

To examine whether there was a difference in the extent of consent and practice as to the radiation safety management, this study conducted the paired sample t-test as to each of the 10 questions. As a result, there was a statistically significant difference at the significant level of 5 percent as to all of the 10 questions. In addition, the perception showed a

Table 4. Extent of safety management practice according to demographic characteristics $(* p<0.05)$.

\begin{tabular}{|l|l|l|l|l|}
\hline \multicolumn{2}{|c|}{ Variables } & Mean & SD & $\begin{array}{l}\text { p-value } \\
\text { (t/F) }\end{array}$ \\
\hline Gender & Male & 17.85 & 5.44 & 0.004 \\
& Female & 20.07 & 5.01 & $\left({ }^{*}\right)$ \\
\hline \multirow{4}{*}{ Age } & Under 29 & 19.94 & 4.64 & \\
& Under 39 & (b) & 5.33 & 0.042 \\
& Under 49 & $17.77(a)$ & 5.72 & $\left({ }^{*}\right)$ \\
& Over 50 & $18.78(a)$ & 6.00 & \\
\hline Marital & Married & 17.90 & 5.41 & 0.07 \\
Status & Single & 19.09 & 5.32 & \\
\hline Educatio & Undergraduate & 18.57 & 5.44 & 0.108 \\
$\mathrm{n}$ & Graduate & 17.32 & 5.33 & \\
\hline \multicolumn{2}{|l|}{ Total } & 18.30 & 5.42 & \\
\hline
\end{tabular}

** (a), (b) and (c) refer to the group classified as a result of Duncan post-hoc analysis.

Int. J. Radiat. Res., Vol. 14 No. 1, January 2016 
lower score than the practice score. Thus, the study subjects could not conduct safety management as much as they perceived it. The mean score as to the perception and practice action for each question is as shown in table 6 . The action with the least level of practice was "I handle the radiation measurement equipment well (Question 8)", "I have measured the dose of radiation control area by myself (Question 7)" and "I store the gown with personal dosimeter in work storage (Question 6)". In contrast, such questions as "I always put on personal dosimeter when working with radiation (Question 1)", "I immediately inform the safety manager when there is any abnormal event in the radiation workplace (Question 10)" and "I am well aware of the risk of radiation exposure and I have acted to reduce radiation exposure for patients and guardians (Question 4)" had a relatively small difference between perception and action. It can be concluded based on figure 1 that all of Item 5, Item 6, Item 7 and Item 8, which are located in the second quadrant, have a low extent of perception and action; thus, they should be given lower priority. All of Item 1, Item 2, Item 3, Item 4 and Item 10, which are located in the third quadrant, have a high extent of perception and action; thus, they require continuing safety management (figure 2 ).

\section{Concluding remarks}

This study has great significance since it contributes to the provision of preliminary information in order to conduct efficiently the education for professionals, which aims to reduce the radiation exposure as to patients in addition to radiation professionals as a health professional.

Conflicts of interest: none to declare.
Table 5. Extent of radiation safety management practice according to work characteristics and work functions $(* p<0.05)$.

\begin{tabular}{|c|c|c|c|c|}
\hline \multicolumn{2}{|c|}{ Variables } & Mean & SD & p-value \\
\hline Career & $\begin{array}{l}\text { Under } 5 \text { years } \\
6 \sim 10 \text { years } \\
\text { Over } 11 \text { years }\end{array}$ & $\begin{array}{l}19.29 \\
18.22 \\
17.55\end{array}$ & $\begin{array}{l}5.28 \\
5.05 \\
5.71\end{array}$ & 0.064 \\
\hline $\begin{array}{l}\text { Working } \\
\text { Hour }\end{array}$ & $\begin{array}{l}\text { Under } 8 \text { hours } \\
\text { Over } 8 \text { hours }\end{array}$ & $\begin{array}{l}18.07 \\
18.57\end{array}$ & $\begin{array}{l}5.36 \\
5.52\end{array}$ & 0435 \\
\hline $\begin{array}{l}\text { Educated } \\
\text { Number } \\
\text { for Safety }\end{array}$ & $\begin{array}{l}\text { Under } 2 \text { times } \\
3 \sim 5 \text { times } \\
6 \sim 10 \text { times } \\
\text { Over } 11 \text { times }\end{array}$ & $\begin{array}{l}20.33(\mathrm{c}) \\
19.00(\mathrm{~b}) \\
17.91(\mathrm{~b}) \\
15.70(\mathrm{a})\end{array}$ & $\begin{array}{l}6.09 \\
5.26 \\
4.87 \\
4.08\end{array}$ & $\begin{array}{c}<0.001 \\
(*)\end{array}$ \\
\hline $\begin{array}{l}\text { Service } \\
\text { Area }\end{array}$ & $\begin{array}{l}\text { Radiology } \\
\text { Radiation } \\
\text { Oncology } \\
\text { Nuclear } \\
\text { Medicine }\end{array}$ & $\begin{array}{l}20.14(c) \\
17.97(b) \\
15.84(a)\end{array}$ & $\begin{array}{l}5.73 \\
5.00 \\
4.15\end{array}$ & $\begin{array}{c}<0.001 \\
\left({ }^{*}\right)\end{array}$ \\
\hline $\begin{array}{l}\text { Hospital } \\
\text { Size }\end{array}$ & $\begin{array}{l}\text { Under } 1,000 \\
\text { beds } \\
\text { Over } 1,000 \\
\text { beds }\end{array}$ & $\begin{array}{l}19.27 \\
17.48\end{array}$ & $\begin{array}{l}5.95 \\
4.84\end{array}$ & $\begin{array}{c}0.004 \\
(*)\end{array}$ \\
\hline Region & $\begin{array}{l}\text { Seoul } \\
\text { Gyeonggi } \\
\text { Others }\end{array}$ & $\begin{array}{l}17.54(\mathrm{a}) \\
18.04(\mathrm{a}) \\
19.81(\mathrm{~b})\end{array}$ & $\begin{array}{l}5.04 \\
5.64 \\
5.35\end{array}$ & $\begin{array}{c}0.017 \\
(*)\end{array}$ \\
\hline
\end{tabular}

** (a), (b) and (c) refer to the group classified as a result of Duncan post-hoc analysis.

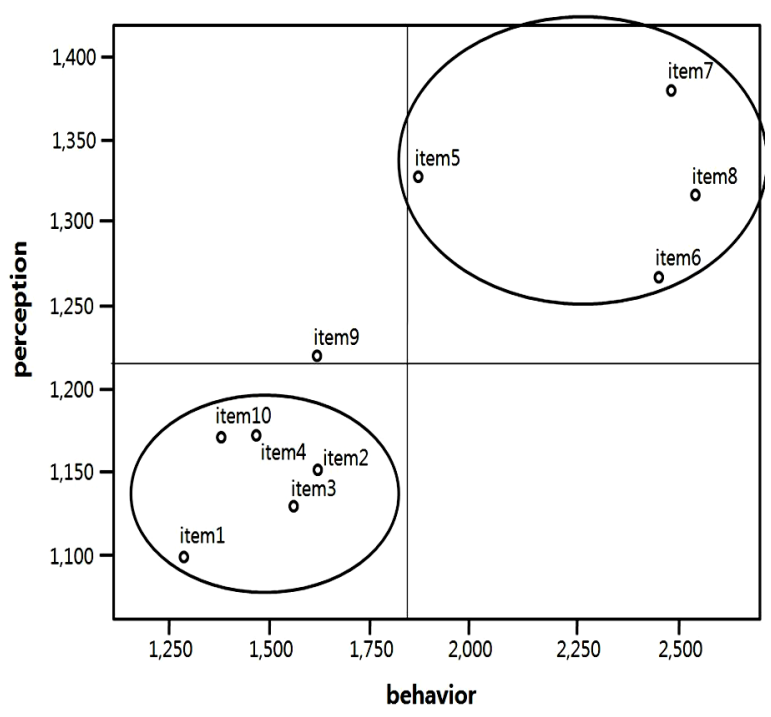

Figure 2. Action and perception plot for 10 items.

Table 6. Verification on difference between perception level and practice as to safety management action.

\begin{tabular}{|l|c|c|c|c|c|c|c|c|c|c|}
\hline & $\begin{array}{c}\text { Question } \\
\mathbf{1}\end{array}$ & $\begin{array}{c}\text { Question } \\
\mathbf{2}\end{array}$ & $\begin{array}{c}\text { Question } \\
\mathbf{3}\end{array}$ & $\begin{array}{c}\text { Question } \\
\mathbf{4}\end{array}$ & $\begin{array}{c}\text { Question } \\
\mathbf{5}\end{array}$ & $\begin{array}{c}\text { Question } \\
\mathbf{6}\end{array}$ & $\begin{array}{c}\text { Question } \\
\mathbf{7}\end{array}$ & $\begin{array}{c}\text { Question } \\
\mathbf{8}\end{array}$ & $\begin{array}{c}\text { Question } \\
\mathbf{9}\end{array}$ & $\begin{array}{c}\text { Question } \\
\mathbf{1 0}\end{array}$ \\
\hline Perception & 1.10 & 1.15 & 1.13 & 1.17 & 1.33 & 1.28 & 1.38 & 1.31 & 1.22 & 1.17 \\
\hline Execution & 1.29 & 1.60 & 1.56 & 1.48 & 1.86 & 2.47 & 2.50 & 2.52 & 1.63 & 1.41 \\
\hline Difference & -.192 & -.447 & -.434 & -.314 & -.531 & -1.194 & -1.129 & -1.210 & -.407 & -.240 \\
\hline
\end{tabular}




\section{Choi, Han, Cho / Analysis of radiation knowledge and safety management}

\section{REFERENCES}

1. The 2007 Recommendations of the International Commission on Radiological Protection. ICRP publication 103. Ann ICRP, 37(2-4): 1-332.

2. F Bouzarjomehri, MH Zare, D Shahbazi (2006) Conventional and spiral CT dose indices in Yazd general hospitals, Iran. International Journal of Radiation Research, 3 (4): 183-189.

3. Alzimami K (2014) Assessment of radiation doses to pediatric patients in computed tomography procedures. Polish Journal Radiology, 79: 344-348.

4. Mora P, Blanco S, Khoury H, Leyton F, Cárdenas J, Defaz MY, Garay F, Telón F, Aguilar JG, Roas N, Gamarra M, Blanco D, Quintero AR, Nader A (2014) Latin American dose survey results in mammography studies under IAEA programme: radiological protection of patient in medical exposures(TSA3). Radiation Protection Dosimetry, pii: ncu20.

5. Hioki K, Araki F, Ohno T, Nakaguchi Y, Tomiyama Y (2014) Absorbed dose measurements for kV-cone beam computed tomography in image-guided radiation therapy. Physics Medical Biology, 59(23): 7297-7313.

6. Harki E and Al-Kinani A (2007) Measurement of organ dose in chest $C T$ examination using Monte Carlo simulation. International Journal of Radiation Research, 4(4): 205-209.

7. Niwa S, Hara T, Kato H, Wada $Y$ (2014) Performance evaluation of CT automatic exposure control on fast dual spiral scan. Nihon Hoshasen Gijutsu Gakkai Zasshi, 70(11):1273-9.

8. Tung MK, Cameron JD, Casan JM, Crossett M, Troupis JM, Meredith IT, Seneviratne SK (2013) Radiation dose in 320-slice multidetector cardiac CT: a single center experience of evolving dose minimization. J Cardiovasc Comput Tomogr, 7(3):157-66.

9. Matsumoto $Y$, Umezu Y, Fujibuchi T, Noguchi Y, Fukunaga J, Kimura T, Hirano N, Hirose T, Sonoda S, Matsumoto R (2014) Verification of the protective effect of a testicular shield in postoperative radiotherapy for seminoma. Nihon Hoshasen Gijutsu Gakkai Zasshi, 70(9): 883-887.

10. Cui S, Jiao L, Tan J, Zhang G, Zhang H, Long W, Fan S, Zhang W (2014) Estimating radiation absorbed dose of individuals nearby 1311-treated Hyperthyroid patients. Health Physics, 106(3): 365-369.

11. Xie T and Zaidi $H$ (2014) Fetal and maternal absorbed dose estimates for positron-emitting molecular imaging probes. J Nucl Med, 55(9): 1459-1466.

12. Matikka $H$ and Virén T (2014) Radiation dose reduction in cone-beam computed tomography of extremities: evaluation of a novel radiation shield. J Radiol Prot, 34(2): N57-63.

13. Gorycki T, Kamiński K, Studniarek M, Szlęzak P, Szumska A (2014) Distribution of the radiation dose in multi slice computer tomography of the chest-phantom study. Pol J Radiol, 14(79): 75-78.

14. Harvey RP (2015) An approach to radiation safety department benchmarking in Academic and medical facilities. Health Phys, 108(1 Suppl 1): S29-36.

15. Kim W, Choi NK, Han JB, Song JN (2014) Study on knowledge and safety management of radiation workers. Journal of the Korea Contents Society, 14(4): 243-248.

16. Kim JH, Ko SJ, Kang SS, Choi SY, Kim C (2011) Analysis of radiation/ radioactivity-related knowledge, perception and behaviors of radiological technologists. Journal of Radiological Science and Technology, 34(2): 123-129.

17.Han EO and Moon IO (2007) Radiological operating techniciants' protective behaviors on radio-medical measures in hospital. The Journal of Korean Society for School Health Education, 8(1): 69-77.

18. Han EO and Kwon DM (2007) Analysis of the trend of knowledge, attitude and behavior related to radiation safety management: focused on radiation workers at medical institute. Journal of Radiological Science and Technology, 30(4): 321-327.

19.Lee DH (2012) Radiation safety management awareness survey of radiation workers in university and study on the effective management. Korea University Master Degree Thesis.

20.Jeon GE (2013) Survey of radiation workers' knowledge, perception, and behavior for radiation. Chonnam University Master Degree Thesis.

21. Kim HS (2001) Study on the knowledge, perception, and behavior about protection of workers who have risk of radiation-exposure in hospital. Yonsei University Master Degree Thesis.

22.Cai JZ (2014) A study about the importance-performance of international liquor exhibition's service quality according to the categories of wine consumers by IPA analysis: focused on the 9th Shanghai wine \& spirits festival, China. Daugu University Master Degree Thesis.

23. Martilla JA, James JC (1977) Importance-performance analysis. Journal of Marketing, 41(1): 13-17.

24. Hammit WE, Bixler DA, Noe FP (1996) Going beyond importance-performance analysis to alalyze the observation-influence of park impacts. Journal of Recreation Administration, 14(1): 45-62.

25.Guadagnolo $F$ (1985) The importance performance analysis: an evaluation and marketing tool. Journal of Park and Recreation Administration, 3(2): 13-22. 
